\title{
CORRESPONDENCE
}

\section{Response to Rai}

\author{
Hypertension Research (2013) 36, 88; doi:10.1038/hr.2012.168; published online 15 November 2012
}

We thank Rai and Mughal $^{1}$ for their comments on our article. ${ }^{2}$ The comments raise an important point about not only peripheral blood pressure (BP) but also central BP for the management of hypertension. As he mentioned, many papers have recently reported on the association between central BP and target organ damage. ${ }^{3-6}$ However, in all of those studies, central BP was evaluated in a clinical setting. In our present guideline, we focused on home BP monitoring, because out-of-office BP has long been recognized to have advantages over traditional clinic BP measurements for the management of hypertension. ${ }^{7,8}$ Unfortunately, as there have been no reports on the efficacy of home measurement of central BP for the management of hypertension, we could not include central BP recommendations in the present guideline. Recently, a device incorporating the indices for not only conventional BP but also central BP throughout a $24-\mathrm{h}$ period has been developed. ${ }^{9,10}$ Therefore, this device would be available for studying the association between out-of-office central BP, and target organ damage and cardiovascular events. From this time onwards, out-of-office central BP data should be accumulated for analysis in future studies.

\section{Satoshi Hoshide ${ }^{1}$, Yutaka Imai ${ }^{2}$ and Kazuomi Kario $^{1}$}

${ }^{1}$ Department of Medicine,

Division of Cardiovascular Medicine, Jichi Medical University School of Medicine, Tochigi, Japan and ${ }^{2}$ Department of Planning for Drug Development and Clinical Evaluation, Tohoku University Graduate School of Pharmacological Science, Snedai, Japan E-mail:kkario@jichi.ac.jp

1 Rai ABS, Mughal SA. Hypertension guidelines : the need for robust surrogate endpoints of central blood pressure. Hypertens Res 2013; 36: 87.

2 Imai $Y$, Kario K, Shimada K, Kawano Y, Hasebe N, Matsuura H, Tsuchihashi T, Ohkubo T, Kuwajima I, Miyakawa M, as members of the Japanese Society of Hypertension Committee for Guidelines for Self-monitoring of Blood Pressure at Home. The Japanese Society of Hypertension Guidelines for Self-monitoring of Blood Pressure at Home (Second Edition). Hypertens Res 2012; 35: 777-795.

3 Kaji Y, Miyoshi T, Doi M, Hirohata S, Kamikawa S, Sakane K, Kitawaki T, Kusachi S, Fukushima Kusano $\mathrm{K}$, Ito $\mathrm{H}$. Augmentation index is associated with B-type natriuretic peptide in patients with paroxysmal atrial fibrillation. Hypertens Res 2009; 32 611-616.

4 Matsumoto C, Tomiyama H, Yamazaki M, Sagawa $Y$ Teraoka K, Shirota T, Miyawaki Y, Yamashina A. Significance of the second peak of systolic blood pressure for identifying both high and low cardiovascular risk states. Hypertens Res 2010; 33: 360-366.

5 Shrestha I, Takahashi T, Nomura E, Ohtsuki T, Ohshita $\mathrm{T}$, Ueno $\mathrm{H}$, Kohriyama T, Matsumoto M. Association between central systolic blood pressure, white matter lesions in cerebral MRI and carotid atherosclerosis. Hypertens Res 2009; 32: 869-874.

6 Nakano T, Munakata A, Shimaura N, Asano K, Ohkuma $\mathrm{H}$. Augmentation index is related to white matter lesions. Hypertens Res 2012; 35: 729-732.

7 Japanese Society of Hypertension. Japanese Society of Hypertension guidelines for the management of hypertension (JSH 2004). Hypertens Res 2006; 29(Suppl): S1-S105.

8 Ogihara T, Kikuchi K, Matsuoka H, Fujita T, Higaki J, Horiuchi M, Imai $\mathrm{Y}$, Imaizumi $\mathrm{T}$, Ito $\mathrm{S}$, Iwao $\mathrm{H}$, Kario $\mathrm{K}$, Kawano Y, Kim-Mitsuyama S, Kimura G, Matsubara H, Matsuura H, Naruse M, Saito I, Shimada K, Shimamoto K, Suzuki H, Takishita S, Tanahashi N, Tsuchihashi T, Uchiyama M, Ueda S, Ueshima H, Umemura $S$, Ishimitsu T, Rakugi H, on behalf of The Japanese Society of Hypertension Committee. The Japanese Society of Hypertension Guidelines for the Management of Hypertension (JSH 2009). Hypertens Res 2009; 32: 3-107.

9 Luzardo L, Lujambio I, Sottolano M, da Rosa A, Thijs L, Noboa O, Staessen JA, Boggia J. 24-h ambulatory recording of aortic pulse wave velocity and central systolic augmentation: a feasibility study. Hypertens Res 2012; 35: 980-987.

10 Williams B, Lacy PS, Yan P, Hwee CN, Liang C, Ting $\mathrm{CM}$. Development and validation of a novel method to derive central aortic systolic pressure from the radial pressure waveform using an $\mathrm{N}$-point moving average method. J Am Coll Cardiol 2011; 57: 951-961. 